\title{
A PALAVRA ENQUANTO BRINQUEDO: REPRESENTAÇÃO DA INFÂNCIA NA OBRA DE ARNALDO ANTUNES
}

André Pinheiro*

\begin{abstract}
Resumo: O tema da infância é um dos aspectos mais relevantes da obra de Arnaldo Antunes, dada a recorrência e o modo peculiar com que é tratado. Portanto, este ensaio propõe realizar uma viagem pelo universo infantil do poeta paulista, discutindo o modo como a experiência da infância é representada em sua produção lírica. Com um projeto de inspiração visual e performática, pode-se afirmar que Arnaldo Antunes faz da poesia uma espécie de brinquedo, permitindo que o leitor se divirta com a palavra no mesmo instante em que realiza a leitura. Logo se percebe, portanto, que a paisagem da infância delineada na obra antuniana é, ao mesmo tempo, de natureza temática e formal.
\end{abstract}

Palavras-chave: Literatura contemporânea. Arnaldo Antunes. Infância.

\begin{abstract}
The theme of childhood is one of the most important aspects of Arnaldo Antunes' works, given the recurrence and the peculiar way that it is treated. Therefore, this paper proposes to make a trip into the infant universe of the poet of São Paulo, discussing how the experience of childhood is represented in his lyrical production. With a visual and performative inspiring design, we can say that Arnaldo Antunes turns poetry into a kind of toy, causing the reader to have fun with the words at the same moment the poem is read. We can see soon that the childhood landscape outlined in the works of Arnaldo Antunes is at the same time of thematic and formal nature
\end{abstract}

Keywords: Contemporary literature. Arnaldo Antunes. Childhood.

\section{Cenas da infância}

Uma rápida sondagem na obra de Arnaldo Antunes já é o suficiente para perceber que a infância é um dos seus temas mais densos e recursivos. Poesia nominalista e empenhada em oferecer uma explicação para a obviedade do mundo, o reconhecimento da sociedade e do homem muitas vezes é concedido pela óptica infantil. Tal representação acontece por vários âmbitos, como se o ser da criança tivesse invadido a alma do poeta e direcionado o rumo do seu olhar. Resulta desse artifício uma produção lírica em que a investigação objetiva do mundo se funde à matéria de ordem inventiva. Essa identificação da atividade poética com o olhar infante parece ser algo inerente ao escritor, pois segundo bem postula Bachelard (2005), "em sua simplicidade, a imagem não tem necessidade de um saber. Ela é a dádiva de uma consciência ingênua. Em sua expressão, é uma linguagem criança" (p. 4).

Mas a representação de cenas da infância constitui apenas o aspecto mais óbvio dessa relação com o universo infantil. Na verdade, Arnaldo Antunes denuncia esse ser criança tanto pelo emprego de uma gramática própria (marcada por uma sintaxe simples, fragmentada e prosaica), quanto pelo modo peculiar de ver o mundo (sempre atento a detalhes que comumente passam despercebidos à compreensão do adulto). Portanto, mais do que um tema, a infância se configura como forma na obra do autor. No mais, a lógica infantil aparece em sua poesia pelo prisma da criatividade, da espontaneidade e do ludismo. Importa ressaltar, contudo, que, ao se voltar para os aspectos inusitados da obviedade, o poeta acaba por apresentar ao leitor um plano de reeducação do olhar.

\footnotetext{
* Doutor em Estudos da linguagem/Literatura comparada pela Universidade Federal do Rio Grande do Norte UFRN. Professor adjunto de Literaturas de língua portuguesa na Universidade Federal do Piauí - UFPI. E-mail: andre.pinheiro@yahoo.com.br
} 
Como grande parte da obra de Arnaldo Antunes é norteada por um projeto de escritura centrado na materialidade do signo poético, não é de se estranhar que a imagem do feto apareça como um dos momentos mais expressivos nesse processo de representação da infância. De certo modo, tal imagem permite que o poeta aborde a fase inicial do desenvolvimento humano de uma maneira mais objetiva, já que o feto ainda não está marcado pelo peso da vivência social. É claro que esse tema também poderia ser retratado de forma particular e afetuosa, como fez a poetisa potiguar Zila Mamede em seu poema "Mãe" (tecelã da rosa que já aflora / em crescimento lento / no seu sangue). No entanto, é preciso admitir que, em função da impossibilidade de vivenciar a experiência da gravidez, essa afetividade maternal soaria um tanto deslocada na voz de um eu-lírico masculino, a quem cabe o papel de ser apenas um observador, um fabulador ou um analista.

Ademais, deve-se levar em conta que a representação do feto é um procedimento, no mínimo, pouco convencional dentro do panorama da tradição literária brasileira. Logo, a escolha desse tema revela simultaneamente a busca pela plasticidade da linguagem e o caráter inusitado da lírica antuniana:

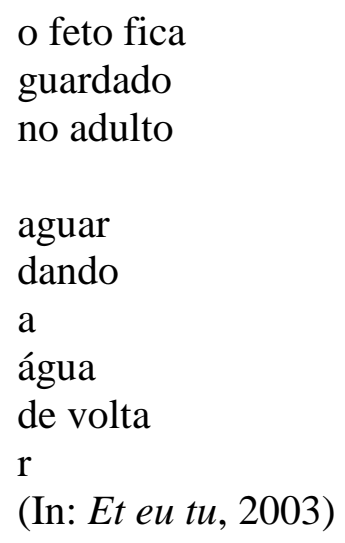

Sem título, o poema é antes de qualquer coisa uma experiência com a própria linguagem, permitindo-se afirmar que o evento retratado e o modo de retratá-lo constituem simultaneamente o seu objeto poético. Tem-se a impressão de que, na tentativa de resignificar um aspecto da realidade imediata, Arnaldo Antunes faz com que uma experiência linguística peculiar se desenvolva no mesmo instante em que a imagem do feto é também gerada.

Apesar de ser um texto lacônico e de natureza formalista, o poeta toca em pontos relevantes acerca do tema. O verbo guardar que aparece na primeira estrofe, por exemplo, tem uma conotação ambígua, pois tanto designa a proteção exercida pelo adulto quanto a sua atitude de vigília e de posse. Trata-se, portanto, de um índice que já revela o caráter elusivo da infância, quase sempre definida a partir de dualidades estabelecidas com a fase madura. Em contrapartida, a imagem da água é um dos elementos responsáveis por manter a perspectiva equilibrada e serena do discurso poético. Símbolo do curso da vida e de fertilidade, a água é, segundo as palavras de Bachelard (2002), "um destino essencial que metamorfoseia incessantemente a substância do ser" (p. 6).

Aliás, é a partir dessa ideia de destino que se introduz uma quebra de expectativa no texto, revelando a falta de perspectiva para a sina da criança. Ao empregar a sentença aguar/dando a água de volta/r quando o mais esperado seria aguardando a hora de nascer, os versos despontam com, pelo menos, duas possibilidades claras de leitura: na primeira, o feto volta, ao nascer, para um lugar onde ele nunca esteve; na segunda, ele volta para o próprio ventre depois de já ter nascido. Há, portanto, uma indefinição em relação ao espaço que essa criança vai ocupar no mundo, como se a própria estrutura poética já 
denunciasse um desiquilíbrio na sociedade. Mas o poema antes se articula pela plasticidade, pelos recursos sonoros e pelos jogos de palavras (dado, dando / água, aguar) do que pelas conjunturas sociais propriamente ditas.

O eu-lírico faz uma constatação e não sente a necessidade de emitir um juízo de valor acerca dela. O feto existe em sua configuração mais plástica e pode-se dizer que o seu retrato muito se aproxima das imagens emitidas por um aparelho de ultrassom. É curioso notar, contudo, que, a despeito desse feitio tão material, o poema não tem um caráter reificado e materialista. Nele, a matéria sensível designa a mais aguda experiência humana - como também é o caso da canção "Grávida", composição de Arnaldo Antunes gravada por Marina Lima no ano de 1991:

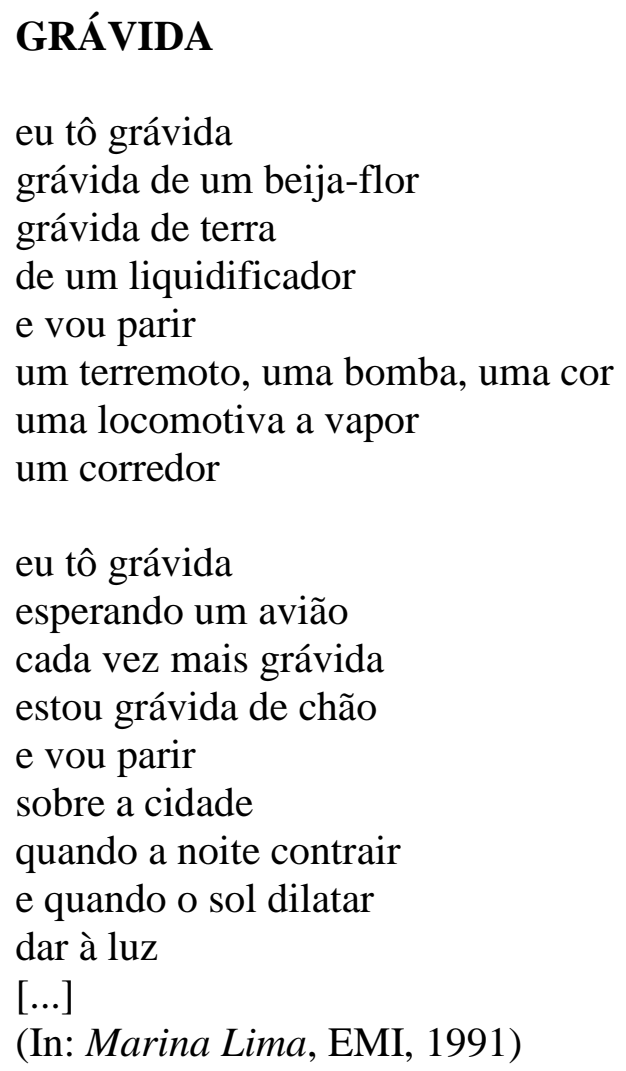

A primeira vista, a listagem de matérias concretas das quais o sujeito lírico engravida pode criar a falsa impressão de que a infância está sendo retratada de forma fria e maquinal. Um olhar mais atento, contudo, revela que a intenção do poeta é exatamente apresentar a realidade cotidiana através de uma perspectiva desautomatizada, livre do discurso afetado pelo senso comum. Nesse sentido, a poesia de Arnaldo Antunes se configura como uma espécie de recriação da óptica infantil, uma vez que ela não adere inteiramente ao raciocínio lógico do adulto. Marcada por um alto grau de estranhamento, a aparente desordem delineada na canção traduz dialeticamente a reorganização do mundo segundo preceitos ínsitos e subjetivos.

Há, portanto, uma coerência interna por trás da composição textual que, em parte, assemelha-se à atitude da criança quando atribui sentido às coisas que lhe surgem virgens de significado. Por outro lado, existe também uma lógica discursiva que permite fazer associações entre as diversas imagens fragmentadas do poema - como a relação entre a gravidez e a substância parida (terra / terremoto) e a projeção na natureza dos eventos vividos pela mulher (quando a noite contrair / e quando o sol dilatar / dar à luz). Assim, o 
olhar do poeta e da criança se fundem para que emerja uma visão de mundo, ao mesmo tempo, ímpar e descentralizadora.

A representação da infância na obra de Arnaldo Antunes encontra-se antes no modo como o discurso é articulado e na visão peculiar da realidade cotidiana do que nos temas infantis propriamente ditos. Marcados pela simplicidade, seus versos encantam porque apresentam um universo tão corriqueiro que o homem já não é mais capaz de percebê-lo. Dessa forma, pode-se dizer que a lírica antuniana se caracteriza por uma espécie de reeducação do olhar, como é o caso do poema "Os avós":

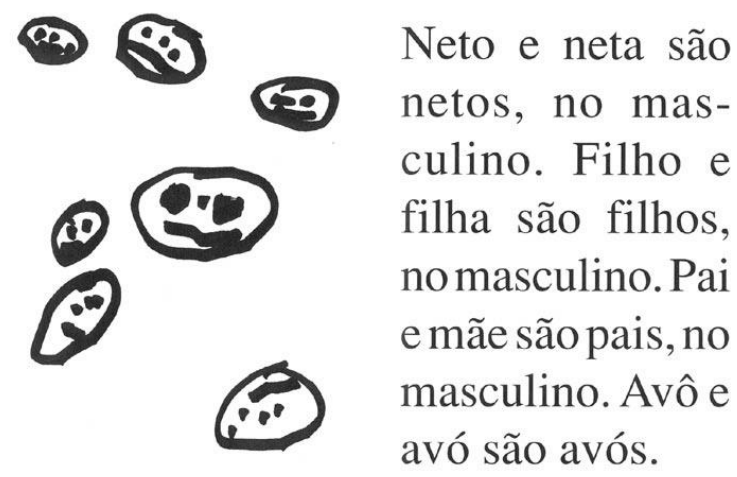

(In: As coisas, 1992)

Vencedor do Prêmio Jabuti de poesia (1993), As coisas é o volume em que essa dimensão infantil aparece de forma mais clara e contundente. E a questão se torna ainda mais interessante quando se leva em conta o fato de que o livro foi ilustrado pela filha do poeta, Rosa Antunes, quando ela tinha apenas três anos de idade. Dialogando com desenhos e rabiscos feitos por uma criança, os poemas de As coisas fazem emergir um mundo que já fora esquecido pelos adultos, motivo que justifica a presença de tantos conceitos, nomes e descrições.

No poema transcrito acima, a discussão acerca de um tema ligado à vivência humana decorre de uma observação linguística, dando provas de que a nossa visão de mundo também se define por uma questão de linguagem. O contraponto estabelecido entre a pluralidade de formas masculinas (netos, filhos e pais) e a unidade formal feminina (avós) acaba por ressaltar a importância dos avós para o processo formativo da criança. Subentende-se, portanto, que a imagem dos velhinhos comporta características feminis, como a brandura, a meiguice e a serenidade. $O$ poeta não se permite, contudo, recair no moralismo cultural, já que sequer o termo feminino aparece para fechar, segundo a lógica paralelística, o poema. Especialmente em As coisas, a lírica de Arnaldo Antunes compõe-se a partir da constatação dos fatos, muito embora a sua natureza estranha quase sempre demande uma reflexão sobre o que o eu-lírico vê, experimenta e descreve.

No fim das contas, a imagem dos avós ressoa de forma serena na mente do leitor, valorizando o que neles existe de afeto e de memória. Aliás, procedimento semelhante é empregado no poema "Tudos", cujo mote principal é a descrição dos animais. Sabe-se que a criança tem uma relação muito afetuosa com os bichos, que - via de regra - figuram como amigo próximo ou como elemento mágico. Dessa forma, Arnaldo Antunes mergulha no cerne do imaginário infantil para tornar mais verossímil a construção do seu ser-criança:

[...] Os rabos dos macacos servem como braços. Os rabos dos cachorros servem como risos. As vacas comem duas vezes a mesma 
comida. [...] Os vidros quando estão bem limpos quase não se vê. [...] Os dentes quando a gente escova ficam brancos. Cabelos quando ficam velhos ficam brancos. [...] Crianças gostam de fazer perguntas sobre tudo. Nem todas as respostas cabem num adulto. (In: As coisas, 1992 - supressões minhas).

Nota-se que os animais não são captados pelo prisma da obviedade funcional. Aqui, eles perdem o seu delineamento objetivo e se transformam em matéria de graça e encantamento. Como uma espécie de enciclopédia minimalista, Arnaldo Antunes compõe uma obra ao mesmo tempo conceitual e imaginativa, fazendo com que esse ser-criança transite entre o universo da ciência e da poesia, entre o mundo observável e a possibilidade de recriá-lo. Apesar de enciclopédico, apenas os conteúdos que interessam ao poeta viram pauta desse catálogo lírico. Depois, algumas aproximações são estabelecidas a partir de uma óptica bem particular - como os dentes limpos e os cabelos velhos, ligados pelo fato de serem brancos. Tais objetos acabam por garantir ao leitor a possibilidade de olhar para o mundo de maneira diversa daquela a que ele está habituado.

\section{A palavra como jogo}

A visualidade dos poemas é outro aspecto de grande relevância para a composição desse universo infantil na obra de Arnaldo Antunes. Aqui, o poeta se aproxima do olhar infante na medida em que registra a sua presença no mundo através de imagens pictóricas. $\mathrm{O}$ desenho é uma das formas mais utilizadas pela criança para expressar seus sentimentos, sonhos, medos e traumas. Por isso mesmo, o desenho figura como um elo entre o sujeito e a realidade cotidiana. De certo modo, a vertente concretista da poesia de Arnaldo Antunes lhe possibilita despertar o menino que gosta de rabiscar a folha de papel - ora porque ainda não atingiu a plenitude da palavra, ora porque reconhece que ela é insuficiente para o processo comunicativo.

No caligrama "Lua, nuvem", por exemplo, o discurso se converte em uma paisagem aberta à contemplação. O significado desse poema só pode ser integralmente depreendido se sua configuração visual também for analisada:

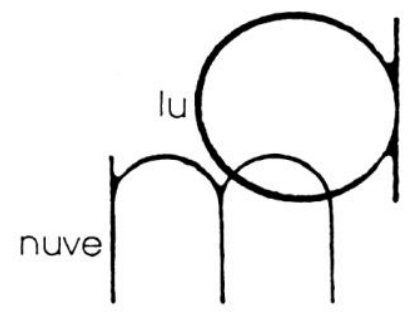

(In: Psia, 1991)

Note-se que a figura da lua é levemente encoberta pela forma sinuosa de uma nuvem. Há, portanto, uma relação opositiva instituída entre o perfeito círculo lunar e a linha ondulante que o rasga. No fundo, a imagem revela que um espaço ordenado está sendo invadido por um segmento de natureza instável. Deve-se levar em consideração que a lua comporta conotações simbólicas herdadas da arte romântica, cujo sentido geral recai sobre a ideia de beleza e graciosidade. Ao romper essa atmosfera idílica, a nuvem lança sobre o espaço uma dose significativa de impureza e, consequentemente, desestabiliza a ordem social vigente. 
A imagem composta pelo poeta não representa apenas o mundo no qual está inserido, mas antes a visão que ele tem desse mundo. Trata-se de um texto que se caracteriza ao mesmo tempo como representação de uma cena (já que define bem a paisagem celeste) e como discurso confessional (já que revela um modo particular de pensar a realidade). É importante que se ressalte esse aspecto porque muitas vezes a poesia visual de Arnaldo Antunes irá comportar um significado social e humano bastante categórico, ainda que, em alguns casos, a significação da parte gráfica esteja condicionada à significação do discurso verbal (a lua suja / de nuvens / surja nua / de nuvens um / dia).

Mas há textos em que o componente lúdico figura como fio condutor do processo criativo. Nesses casos, o poema perde o tom de seriedade proveniente das discussões sobre o homem e o mundo e se transforma em uma espécie de brincadeira com a palavra. De modo geral, tem-se a impressão de que poesia é um objeto palpável que se pode facilmente manusear:

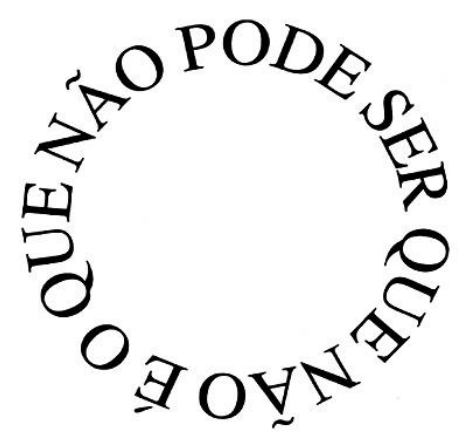

(In: Psia, 1991)

O poema "O que" nasceu de uma canção gravada na época em que Arnaldo pertencia ao grupo de rock Titãs. Somente anos depois, o poeta resolveu dar-lhe um tratamento modular e visual. Mas o que realmente interessa neste caso é o fato de o texto permitir que o leitor tenha um contato com o livro de forma diversa daquela imposta pela tradição literária brasileira. Formando versos ao parar em diferentes pontos do círculo, o poema torna a leitura mais dinâmica e o leitor atua de maneira mais autônoma. A palavra neste contexto funciona antes como elemento desestruturador (no sentido de que há uma desordem na linearidade do discurso) do que como algo elucidativo. Isso não significa dizer que o poema esteja vazio de significado. Bem pelo contrário, aqui a própria forma é o elemento significante. É propriamente ela que aponta para a negação da tradição literária e para a adesão à contemporaneidade.

O poema também suscita um debate sobre os limites que definem os gêneros literários. Como parte de um percurso histórico, é natural que a poesia contemporânea tenha formas diferentes de captar seus objetos, obrigando a teoria da literatura a manter-se sempre atualizada acerca do assunto. Não restam dúvidas de que hoje a linguística se encontra em um estágio mais avançado em relação a essa temática. Quase sempre confundindo os conceitos de tipologia, gêneros e formas literárias, a teoria da literatura dificilmente aborda a matéria dos gêneros a partir da relação que eles estabelecem com as práticas sociais - exceção feita, claro, aos estudos memoráveis de Georg Lukàcs e Mikhail Bakhtin. Um modelo de análise muito estrutural se revela tanto mais ineficaz quando precisa dar conta da experiência artística contemporânea, que, via de regra, tende a rejeitar normas demasiado rígidas e fronteiras muito bem delineadas. 
De certo modo, a obra de Arnaldo Antunes é uma prova de que é necessário rever a questão dos gêneros no âmbito dos estudos literários. O poeta soube captar com maestria os estímulos da sociedade hodierna e transformá-los em uma estrutura poética de natureza vanguardista. No bojo de suas inovações encontram-se procedimentos inusitados, como poemas que saem do suporte tradicional do livro e ganham representação tridimensional ou cibernética; textos que primeiro aparecem como letra de canção e depois surgem em volumes de poesia com leves alterações (ou vice-versa); acervo fotográfico tratado como se fosse um conjunto de poemas; emprego exagerado de recursos visuais; poemas vocalizados e performáticos etc. De certo modo, essa articulação caótica da poesia antuniana é um reflexo do mosaico sociocultural da era contemporânea e o retrato mais contundente dos caminhos que a literatura pode trilhar na era tecnológica.

Por fim, além dos recursos visuais, os efeitos sonoros também fazem parte dessa brincadeira com as palavras promovida pelo poeta paulista. Tanto o som quanto o silêncio cumprem uma função importante dentro desse processo construtivo. Com pleno domínio do emprego de formas e estruturas poéticas, Arnaldo Antunes sabe muito bem quando um texto demanda um alto grau de contração linguística ou uma proliferação de vozes. Abaixo, tem-se um exemplo de uma expressão minimalista:

$$
\begin{aligned}
& \text { O sim. } \\
& \text { A mão. } \\
& \text { (In: Psia, 1991) }
\end{aligned}
$$

Impresso com uma fonte pequena no meio de uma página branca, o poema parece retratar uma cena de casamento reduzida a seus elementos essenciais: o aceite do parceiro, a mão para se pôr a aliança e a consolidação do ato matrimonial. Todo o restante da situação fica subjugado ao peso do silêncio para que não se perturbe a intimidade do novo casal.

No poema "Agá", por sua vez, a repetição exaustiva da palavra quase facilmente leva o leitor a provar uma sensação de enfado. Na tentativa de mimetizar a gagueira humana, o poeta cria um jogo sonoro que se desdobra numa espécie de eco:

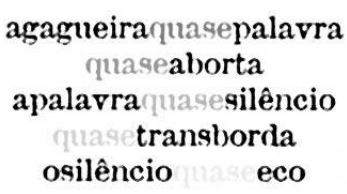

(In: Dois ou + corpos no mesmo espaço, 1997)

O reconhecimento e a assimilação dos sons constituem um momento importante no processo de aprendizagem da criança, já que a ação de ouvir também é uma forma de interagir com mundo circundante. $\mathrm{O}$ ato de nomear, tão usual na primeira idade, nada mais é do que uma tentativa de designar uma identidade sonora para as coisas que vemos. Ao escolher o som como objeto poético, Arnaldo Antunes acaba por reproduzir formalmente esse momento em que a criança começa a constituir o mundo a sua volta. Os recursos utilizados para tanto são quase onomatopeicos, como se o poeta desejasse que a imitação da realidade fosse 
reduzida ao ruído, ao momento mais primitivo da fala humana - como também parecem ser primitivos os desenhos, feitos por sua filha, que ilustram o livro As coisas.

Aqui o poema também funciona como uma espécie de jogo, como diversão. O leitor certamente o sentirá como um trava-língua - escolha formal muito acertada, já que o discurso poético busca reproduzir o som da gagueira. A verdade é que Arnaldo Antunes se relaciona com a palavra de forma semelhante como a criança se relaciona com um brinquedo. A matéria concreta e a visualidade de seus versos dão a impressão de que o leitor está diante de um objeto quase tridimensional. Depois, as constantes mudanças de suporte de um mesmo texto provam que a poesia é para ele algo que se monta e desmonta ao seu gosto e interesse. Talvez seja exatamente por isso que a lírica antuniana venha cada vez mais ganhando terreno no cenário nacional e internacional, afinal, não deve existir coisa mais interessante do que ter a literatura como seu brinquedo favorito:

\section{CULTURA}

o girino é o peixinho do sapo

o silêncio é o começo do papo

o bigode é a antena do gato

o cavalo é pasto do carrapato

o cabrito é o cordeiro da cabra

o pescoço é a barriga da cobra

o leitão é um porquinho mais novo

a galinha é um pouquinho do ovo

o desejo é o começo do corpo

engordar é a tarefa do porco

a cegonha é a girafa do ganso

o cachorro é um lobo mais manso

o escuro é a metade da zebra

as raízes são as veias da seiva

o camelo é um cavalo sem sede

tartaruga por dentro é parede

o potrinho é o bezerro da égua

a batalha é o começo da trégua

papagaio é um dragão miniatura

bactérias num meio é cultura

(In: Cultura, 2012)

\section{Referências}

ANTUNES, A. Psia. São Paulo: Iluminuras, 1991.

. Tudos. São Paulo: Iluminuras, 1991.

As coisas. São Paulo: Iluminuras, 1992. 
2 ou + corpos no mesmo espaço. São Paulo: Perspectiva, 1997.

. ET eu tu. São Paulo: Cosac \& Naify, 2003.

. Cultura. São Paulo: Iluminuras, 2012.

BACHELARD, G. A poética do espaço. Trad. Antônio de P. Donese. São Paulo: Martins Fontes, 2005.

FERNANDES JR, A. Os entre-lugares do sujeito e da escritura em Arnaldo Antunes. Curitiba: Appris, 2012.

MAMEDE, Z. Navegos. A herança. Natal: EDUFRN, 2003.

PIETROFORTE, A. V. Arnaldo Antunes e a Nuvem Lua. In: O discurso da poesia concreta. São Paulo: Annablume/FAPESP, 2011.

SANTOS, A. Arnaldo canibal Antunes. São Paulo: Versos, 2012.

Recebido em: julho 2014.

Aprovado em: dezembro 2014. 